In conclusion, many of the NICE recommendations will prove beneficial in ensuring that women with preexisting or gestational diabetes receive comprehensive care that aims to minimise risks to mother and baby. The recommendations will be most helpful for clinicians managing predominantly white women with type 1 diabetes and a high uptake of medical care and low deprivation; however, in areas with an increasingly obese, ethnically diverse population and a high risk of type 2 and gestational diabetes, implementation will be more challenging.

Contributors: Both authors contributed to the conception, drafting, and revision of the article and gave final approval of the version to be published. LCC is the guarantor.

Competing interests: None declared.
Provenance and peer review: Commissioned; not externally peer reviewed.

1 Diabetes care and research in Europe: the Saint Vincent declaration [workshop report]. Diabet Med 1990;7:360.

2 Confidential Enquiry into Maternal and Child Health. Diabetes in pregnancy: are we providing the best care? Findings of a national enquiry: England, Wales and Northern Ireland. London: $\mathrm{CEMACH}$ 2007.

3 Confidential Enquiry into Maternal and Child Health. Saving mothers lives: reviewing maternal deaths to make motherhood safer-20032005. [The seventh report on Confidential Enquiries into Maternal Deaths in the United Kingdom.] London: CEMACH, 2007

4 Pöyhönen-Alho MK, Teramo KA, Kaaja RJ, Hiilesmaa VK. 50 gram oral glucose challenge test combined with risk factor-based screening for gestational diabetes. Eur J Obstet Gynecol Reprod Bio 2005;121:34-7.

5 Crowther CA, Hiller JE, Moss JR, McPhee AJ, Jeffries WS, Robinson JS Australian Carbohydrate Intolerance Study in Pregnant Women (ACHOIS) Trial Group. Effect of treatment of gestational diabetes mellitus on pregnancy outcomes. N Engl J Med 2005;352:2477-86.

\title{
TEACHING ROUNDS
}

\section{Role modelling-making the most of a powerful teaching strategy}

\author{
Sylvia R Cruess, Richard L Cruess, Yvonne Steinert
}

Centre for Medical Education, McGill University, 1110 Pine

Avenue West, Montreal, QC

Canada H3A 1 A3

Correspondence to: S R Cruess

sylvia.cruess@mcgill.ca

BMJ 2008;336:718-21 doi:10.1136/bmj.39503.757847.BE

This series provides an update on practical teaching methods for busy clinicians who teach. The series advisers are Peter Cantillon, senior lecturer in the department of general practice at the National University of Ireland, Galway, Ireland, and Yvonne Steinert, professor of family medicine, associate dean for faculty development, and director of the Centre for Medical Education at McGill University, Montreal.

\section{Teachers need to be aware of the conscious} and unconscious components of learning from role modelling, so that the net effect of the process is positive

Educating future generations of physicians is one of the privileges and obligations of the medical profession. As an important part of this process, doctors historically have patterned their activities on those of practitioners whom they respect and trust. These have been called role models, "individuals admired for their ways of being and acting as professionals." Both consciously and unconsciously, we model our activities on such individuals. ${ }^{2}$

Although role modelling is at the heart of "character formation," "3 medical students and junior doctors have observed that many clinical teachers are poor role models. In one study less than half of the teachers were identified as positive role models. ${ }^{4}$ In another, half of the clinical clerks and a third of the residents surveyed felt that their teachers were not good role models for doctorpatient relationships. ${ }^{1}$ Clearly, this is a situation that should concern us and the institutions in which we work.

Learning from role models occurs through observation and reflection, and is a complex mix of conscious and unconscious activities (fig 1). ${ }^{5} \mathrm{We}$ are all aware of the conscious observation of behaviours, but understanding the power of the unconscious component is essential. Active reflection on the process can convert an unconscious feeling into conscious thought that can be translated into principles and action. In an equally powerful process, observed behaviours are unconsciously incorporated into the belief patterns and behaviours of the student.

Role models differ from mentors. ${ }^{6}$ Role models inspire and teach by example, often while they are doing other things. Mentors have an explicit relationship with a student over time, and they more often direct the student by asking questions and giving advice freely.

\section{What makes for an effective role model?}

As teachers we are capable of wide variation in our performance as role models, and we can demonstrate both positive and negative behaviours in a single encounter, as illustrated in the first vignette (box 1).

The characteristics of role models have been well documented $^{134-10}$ (fig 2) and can be divided into three categories:

Clinical competence encompasses knowledge and skills, communication with patients and staff, and sound clinical reasoning and decision making. All of these skills must be modelled as they lie at the heart of the practice of medicine.

Teaching skills are the tools required to transmit clinical competence. A student centred approach incorporating effective communication, feedback, and opportunities for reflection is essential to effective role modelling.

Personal qualities include attributes that promote healing, such as compassion, honesty, and integrity. Effective interpersonal relationships, enthusiasm for practice and teaching, and an uncompromising quest for excellence are equally important. 
"We must acknowledge . . that the most important, indeed the only, thing we have to offer our students is ourselves. Everything else they can read in a book." - D C Tosteson ${ }^{19}$

\section{Where does role modelling take place?}

Medical education is complex and students can observe role models in a variety of educational settings. We now understand that there is a formal, an informal, and a hidden curriculum. ${ }^{10}$ Role models function in all three.

The formal curriculum is outlined in mission statements and course objectives, detailing what faculty members believe they are teaching. Role modelling certainly takes place here, and the conduct of medical teachers at this level can have a profound effect. Teachers who show passion and enthusiasm for medicine can be extremely effective; failing to do so is to miss a valuable opportunity.

The informal curriculum, which consists of unscripted, unplanned, and highly interpersonal forms of teaching and learning, is very powerful. All role models, from peers to senior doctors, function in the informal curriculum, ${ }^{1011}$ and many of the corrosive effects of negative role modelling are experienced here. $^{412}$ As shown in the second vignette (box 1), conversations in both formal and informal settings reveal and transmit important attitudes and values.

Finally, a set of influences, which are largely hidden, function at the level of the organisational culture and structure of the institution. The influence of this hidden curriculum on role modelling can be profound, as many of the barriers to effective role modelling can be found here. For example, an institutional culture that promotes overwork, leaving insufficient time for harried clinical teachers to promote the type of

\section{Box 1 Role modelling vignettes}

\section{1: In the middle of the night}

A house doctor on duty in the intensive care unit at night pages the consultant on call, Dr Smith, to inform her that a postoperative patient is not doing well. The consultant is obviously annoyed at being called in the middle of the night. Although she answers the questions and finally agrees to come in, the conversation is unpleasant and filled with tension, as Dr Smith is abrupt to the point of rudeness.

\section{2: In the cafeteria}

In the cafeteria, students and their mentor overhear Dr Reed, a senior surgeon, describing a patient in derogatory terms, using the patient's name. The mentor asks to speak to Dr Reed privately, and reminds him that he is in a public place, violating patient confidentiality and failing to show respect.

\section{3: In the clinic}

A final year medical student on rotation in a general practitioner's office finds that a patient with metastatic breast cancer is extremely upset and worried about her future. The general practitioner, DrJones, is extremely busy, with many patients waiting. Nevertheless, he enters the consultation room with the student, sits down and takes the patient's hand, empathises with her concerns, and explains that he is very pressed for time; he also arranges a special appointment with her at a later date when he will have time to reassure her and answer her questions.

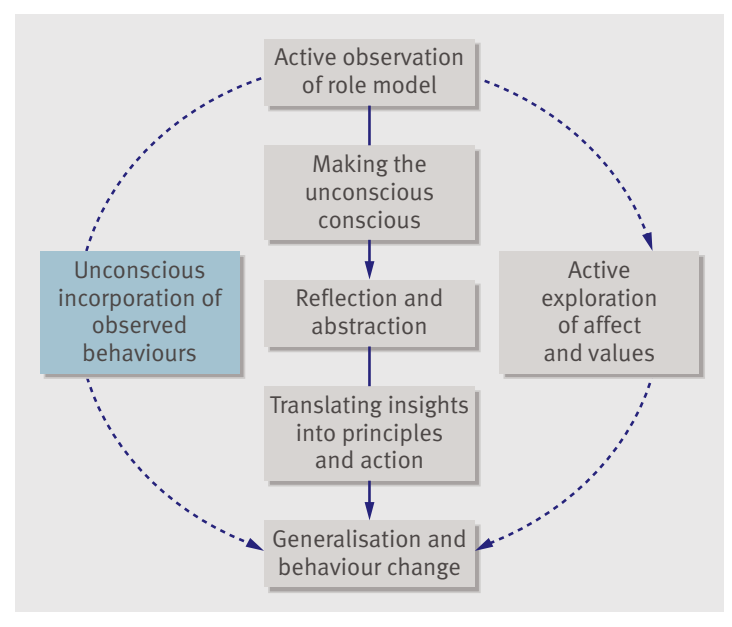

Fig $1 \mid$ The process of role modelling ${ }^{7}$

reflective practice needed to demonstrate best practices among students, is detrimental to effective role modelling. Similarly, a culture that tolerates inadequate clinical care or poor interpersonal relationships inhibits positive modelling, as do administrative decisions that fail to show appreciation and support, both financial and non-financial, of those who are trying to be exemplary.

\section{How can role modelling be improved?}

The desire to better our own performance is a necessary first step in improving role modelling. Two areas need to be addressed: the personal level, where we analyse our own strengths and weaknesses as role models, and the organisational level, where we consider the impact of the institutional culture in which we teach.

\section{Strategies to improve personal performance}

Doctors can improve their teaching skills and possibly their effectiveness as role models. ${ }^{2-13}$ Box 2 lists some strategies that can help to improve role modelling.

\section{Awareness of being a role model}

The conscious recognition of the importance of role modelling as a teaching and learning strategy, and the positive or negative impact of what we are modelling, is fundamental to improving performance. For example, is Dr Smith (vignette 1) aware of the impact of her "rude behaviour"- or of the fact that she is condoning it? We are role models at all times - when we are teaching and when we are in social situations. ${ }^{9}$ We must also share our awareness with our students. For example, it is important for Dr Jones (vignette 3) to explain the encounter with the patient so that the student will reflect on and understand some of the lessons learnt.

\section{Time to teach}

Despite the challenges of clinical demands, we must "protect time" in order to facilitate dialogue, reflection, and debriefing, all of which are needed to make the lessons learnt through role modelling apparent to the learner. ${ }^{1415}$ For example, had Dr Smith (vignette 1) 
talked about her personal distress in the middle of the night, she would have given an important-and positive - message to the student. The lack of conversation led to a missed opportunity for learning.

Negative attitudes, such as those shown by Dr Smith (vignette 1) and Dr Reed (vignette 2), are as powerful as the positive ones demonstrated by the mentor in vignette 2 and Dr Jones in vignette 3 . Consciously modelling competence, positive attitudes, and enthusiasm for the practice of medicine, as Dr Jones demonstrates, can be transformative. ${ }^{14}$ However, we need to ensure that the behaviours being modelled are made explicit to the learner.

The importance of reflection: making the implicit explicit The ability to be conscious of, and reflect on, the behaviours and attributes that we are demonstrating is crucial to effective role modelling. Whenever possible, we should examine and explain what we do in the presence of students, junior doctors, and colleagues. This has been called "reflection in action." ${ }^{14}$ It is also helpful to discuss with students the impact of the encounter on the patient, the student, and oneself after it has occurred-"reflection on action." If we then relate this experience to future actions, we are engaged in "reflection for action."

Many situations include a mix of positive and negative role modelling; reflecting on these experiences provides valuable lessons to students. For

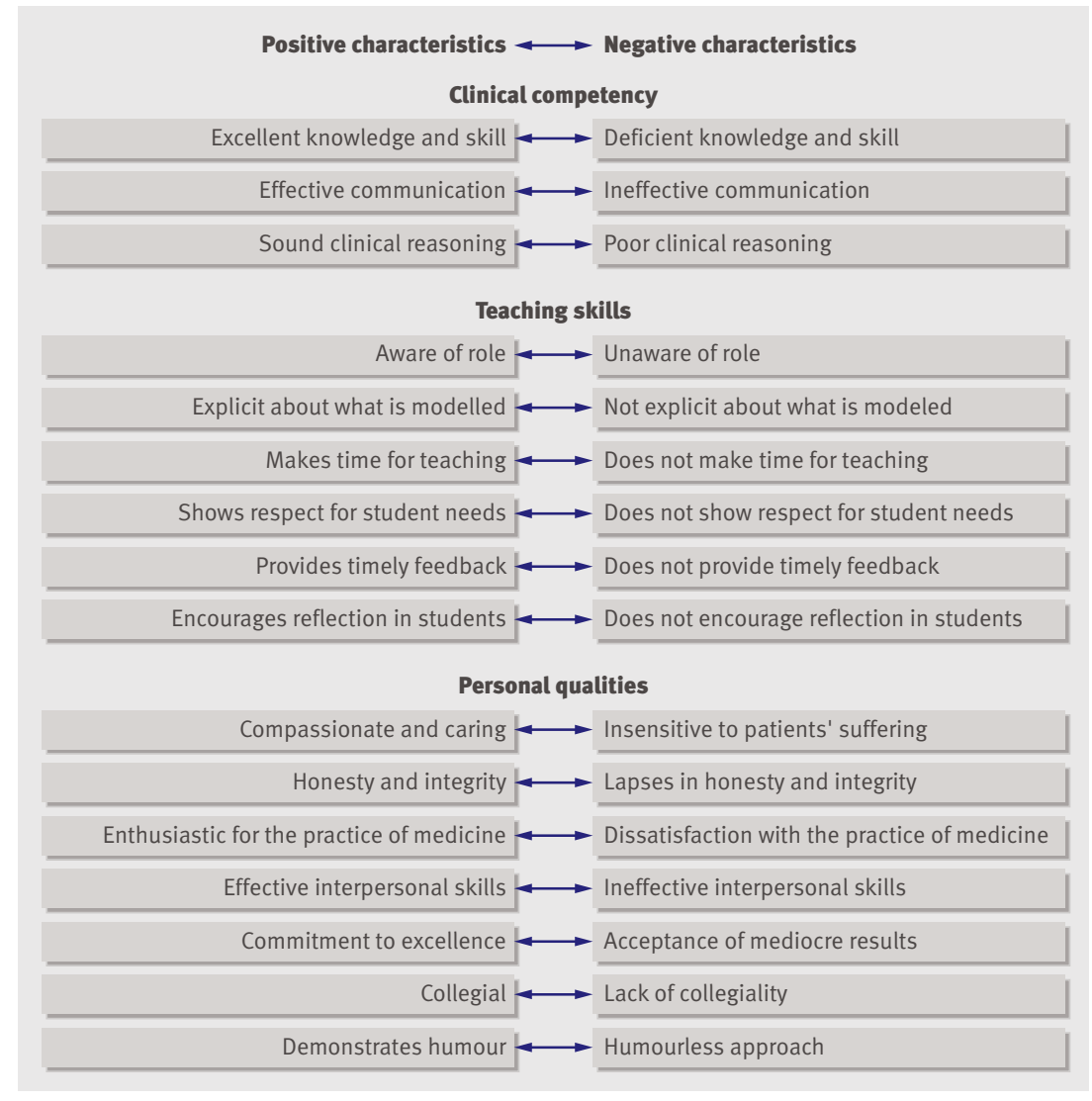

Fig 2 | Characteristics of role models

\section{Box 2 Strategies to improve role modelling}

- Be aware of being a role model

- Demonstrate clinical competence

- Protect time for teaching

- Show a positive attitude for what you do

- Implement a student centred approach to teaching

- Facilitate reflection on clinical experiences and what has been modelled

- Encourage dialogue with colleagues

- Engage in pertinent staff development

- Work to improve the institutional culture

- Whenever possible be explicit about what you are modelling

example, the mentor in vignette 2 demonstrates positive modelling through self regulation. The fact that Dr Smith (vignette 1) does come in during the middle of the night shows both commitment and altruism. However, without thinking about these events, students may not learn from what they have observed. Although important components of role modelling will always remain implicit, a conscious effort to articulate what we are modelling, and to make the implicit explicit, will benefit both the student and role model.

\section{Participating in staff development}

Staff development programmes designed to improve teaching skills are now widely available, both within institutions and at scientific meetings. ${ }^{16}{ }^{17}$ Some universities offer programmes specifically designed to improve role modelling. These can be of great value if they encourage reflection by the role models. Volunteering to participate in such activities indicates a desire to improve.

\section{Strategies to improve the institutional culture}

Given the multitude of factors that impact role modelling, working to improve the institutional culture in which we work cannot be ignored. The important institutional barriers to effective role modelling include an organisational structure that encourages overwork, resulting in insufficient time for teaching ${ }^{15}$; a lack of institutional support for teaching ${ }^{1011}$; and a culture that accepts inadequate patient care or poor relationships between members of the healthcare team. ${ }^{11}$ As individuals dedicated to student learning, we must work to overcome these barriers and take advantage of opportunities that can help to improve the environment in which we teach. Methods for doing so depend on the local organisation and culture; they include raising awareness, pointing out deficiencies, reinforcing strengths, analysing the local environment, and proposing remedial action, which will often include staff development. The object is to create an environment that supports positive role modelling. 


\section{KEY POINTS}

Role modelling is a powerful teaching tool for passing on the knowledge, skills, and values of the medical profession, but its net effect on the behaviour of students is often negative rather than positive

By analysing their own performance as role models, individuals can improve their personal performance

Strategies are available to help doctors become better role models:

Being aware of the impact of what we are modelling (be it positive or negative)

Protecting time to facilitate dialogue, reflection, and debriefing with students

Making a conscious effort to articulate what we are modelling, and to make the implicit explicit
2 Skeff KM, Mutha S. Role models-guiding the future of medicine. NEngl J Med 1998;339:2015-7.

3 Kenny NP, Mann KV, MacLeod HM. Role modeling in physicians' professional formation: reconsidering an essential but untapped educational strategy. Acad Med 2003;78:1203-10.

4 Wright SM, Kern DE, Kolodner K, Howard DM, Brancati FL. Attributes of excellent attending-physician role models. $N$ Engl J Med 1998;339:1986-93.

5 Epstein RM, Cole DR, Gawinski BA, Piotrowski-Lee S, Ruddy NB. How students learn from community-based preceptors. Arch Fam Med 1998;7:149-54.

6 Ricer RE. Defining preceptor, mentor, and role model. Fam Med 1998;30:328.

7 Paice E, Heard S, Moss F. How important are role models in making good doctors? BMJ 2002;325:707-10.

8 Wright SM. Examining what residents look for in their role models. Acad Med 1996;71:290-2.

9 Wright SM, Wong A, Newill C. The impact of role models on medical students. J Gen Int Med 1997;12:53-6.

10 Hafferty FW. Beyond curriculum reform: confronting medicine's hidden curriculum. Acad Med 1998;73:403-7.

In conclusion, role models do not only function at the bedside, in the clinic, or in an office. Role models in medicine fulfil their roles in virtually any situation in which a student can observe a clinical teacher. ${ }^{18}$ In doing so, it is important to model a lifestyle characteristic of a professional. We must also recall that being an effective role model is an ideal to be pursued. No one is a perfect role model at all times. Our objective is to be as consistently good as we can be.

Contributors: All authors contributed equally to conceptualising and writing the manuscript.

Competing interests: None declared.

Provenance and peer review: Commissioned; not externally peer reviewed.

1 Cote L, Leclere $\mathrm{H}$. How clinical teachers perceive the doctor-patient relationship and themselves as role models. Acad Med 2000;75:1117-24.
11 Inui TS A flag in the wind: educating for professionalism in medicine. Washington, DC: Association of American Medical Colleges, 2003.

12 Baldwin DC, Daugherty SR, Rowley BD. Unethical and unprofessional conduct observed by residents during their first year of training. Acad Med 1998;73:1195-200.

13 Skeff KM, Stratos GA, Berman J, Bergen MR. Improving clinical teaching. Evaluation of a national dissemination program. Arch Intern Med 1992;152:1156-61.

14 Schon DA. Educating the reflective practitioner: toward a new design for teaching and learning in the professions. San Francisco: JosseyBass, 1987.

15 Ludmerer KM. Time to heal. Oxford: Oxford University Press, 1999.

16 Steinert Y, Cruess RL, Cruess SR, Boudreau JD, Fuks A. Faculty development as an instrument of change: a case study on teaching professionalism. Acad Med 82:1057-64.

17 Steinert Y, Mann K, Centeno A, Dolmans D, Spencer J, Gelula M, et al. BEME guide No 8: a systematic review of faculty development initiatives designed to improve teaching effectiveness in medical education. Med Teach 2006;28:497-526.

18 Althouse LA, Stritter FT, Steiner BD. Attitudes and approaches of influential role models in clinical education. Adv Health Sci Educ Theory Pract 1999;4:111-22.

19 Tosteson DC. Learning in medicine. N Engl J Med 1979;301:690-4.

\section{A lesson relearnt}

At medical school, the importance of introducing yourself to the patient was continually emphasised. The first box on any OSCE (objective structured clinical examination) mark sheet was devoted to this simple, but fundamental tenet of being a doctor. For a "clear pass," one had to state one's name and role and clarify the patient's preferred form of address.

These were easy marks to be had, so I learnt a spiel by rote: "Hello Mr/Ms ......, my name is ...., I'm a medical student, would it be alright if I examined you?" I must have repeated this, or some variation thereof, hundreds of times during my three years as a clinical student. I remember during one mock OSCE practice, the doctor leading the session enthusiastically congratulating us on introducing ourselves clearly. I thought this a bit over the top, but he went on to say that many doctors doing postgraduate examinations often forgot to introduce themselves and launched straight into examining the patient or taking the history. I thought this unlikely, given that introducing oneself is something learnt on the first day of medical school. How wrong I was.

Thus, one afternoon I found myself going to prescribe intravenous fluids for one of our postoperative patients. I already knew the patient; I had met her on the ward round every morning for the past week, albeit scribbling notes hurriedly at the end of the bed. I picked up her fluid balance chart and started asking her about how much she had been drinking and whether she felt thirsty. I was trying to calculate her fluid balance when she asked: "But what's your name, doctor?" I paused in the midst of my calculations and answered her question somewhat sheepishly.

Subsequently, I reflected on this incident and its implications. I was surprised that I had forgotten to introduce myself-something that just a few months earlier would have been unthinkable. I knew that I had become more efficient during my first few weeks as a doctor, due in part to my being able complete the same tasks in less time. After my first week on call, I no longer sat down to take a history; instead, I wrote my notes after seeing the patient, and my examinations became slicker and more focused. The second reason for my new found efficiency was that in the transition from medical student to doctor, I had discarded things I considered unnecessarytactile vocal fremitus, for example, practised obsessively for finals and forgotten soon after. This episode, however forced me to reconsider this enthusiastic pruning and to wonder whether, far from being efficient, I had already discarded too much.

So I have taken a step back and try, especially when I am busy, to pause, take stock, and think about how I might have approached the situation as a medical student and whether I should be equally thorough now. And I have resolved to introduce myself properly to all patients, although I accept that most cannot pronounce, let alone remember, my name.

Vasandhara Mahendrayogam foundation year doctor West Suffolk Hospital, Bury St Edmunds vasmahendra@hotmail.com 